Gadjah Mada International Journal of Business

September 2004, Vol. 6, No. 3, pp. 309 - 322

\title{
INTRAGROUP COOPERATION VS. INTRAGROUP COMPETITION A Meta-Analytical Study
}

\author{
Ainun Na'im*
}

This study examines whether intragroup cooperation outperforms intragroup competition. Intragroup cooperation is a work setting when individuals in a group perceive that their goal attainments are positively related; while intragroup competition is a work setting when individuals in a group perceive that their goal attainments are negatively related. Performance is defined as group productivity level, speed of solving problems, and quality of the group outcomes.

Meta-analytical method is used to test the hypothesis. The method combines and compares eight studies from various research disciplines i.e., education, psychology, organization, and business and accounting. The studies being analyzed also vary in terms of the research and experimental setting such as manufacturing operations and problem solving games.

Meta-analytical study is relatively rare in Indonesia, so that this study is important to introduce and to show the importance and the benefit of the analysis for concluding a large number and different research in a similar domain of research question. In a simple term, a meta-analysis is a quantitative literature review. However, the analysis has a more powerful procedure (than the conventional literature review) to indicate more clearly, and in quantitative terms, the consistency, the differences and similarities of previous studies.

The authorfound that intragroup cooperation outperforms intragroup competition is held across different experimental subject educational backgrounds such as education, psychology, and business and accounting. However, the extent of the difference in performance is higher in the subjects with psychology background than that of the subjects with business and accounting background. The reason is that business and accounting subjects are more exposed to competitive environments than those whose backgrounds are psychology and sociology.

Keywords: intragroup competition; intragroup cooperation; meta-analysis; performance

* I highly appreciate comments from the reviewers, and I take fully the responsibility for the article. 


\section{Introduction}

This study examines whether intragroup cooperation outperforms intragroup competition. Intragroup cooperation has been defined as when individuals in a group perceive their goal attainments are positively related. A member's action toward his/her goals facilitates attainment of another member's goals. In contrast, in intragroup competition, individuals in a group perceive their goal attainments as negatively related. A member is action toward his/her goals interferes and makes less likely the attainment of another member's goals (Deutsch 1949; Tjosvold 1984). Performance is defined as group productivity level, speed of solving a problem, or quality of group outcomes.

Deutsch's (1949) finding that cooperative groups have higher performance than competitive groups has been tested and expanded by a large number of studies in education and social psychology. Johnson et al. (1981) provided a review and meta-analysis of 122 of those studies, and reported an effect size of 0.78 on the relationship that intragroup cooperation outperforms intragroup competition. Recently, cooperation theory became of interest to organizational and accounting setting (Young et al. 1992; Ravenscroft and Haka 1996). This is because, since 1980 s, the teamwork and cooperative group approach become more popular in the U.S. due to international, especially Japanese, management system influence (Lawler 1986).

Cooperation theory has been developed to include the relationship between cooperative and individual efforts, cooperative and competitive efforts, intergroup competition and cooperation, and intragroup cooperation and competition. The domain of this study does not include all those variables, but focuses on intragroup cooperation and intragroup competition.

This study examines the intragroup cooperation and competition issue by combining and comparing the studies from educational and social psychological research with organizational and accounting research. The motivation behind this study is to analyze whether the previous results that intragroup cooperation outperforms intragroup competition holds across educational and social psychology, and business and accounting studies; across male and female subjects, of experiments, and across different tasks.

This study is important for two reasons. First, cooperation and competition setting are critical in most of business, management and strategic issues. The issue of cooperation and competition can be associated with the strategic choices, i.e. whether a firm should take alliance, merger or acquisition strategy. In internal management of firms, cooperation and competition is relevant with choices of performance evaluation scheme to motivate managers and employees. Second, in research, the issues of cooperation and competition is very relevant in group dynamic literature, compensation and performance evaluation schemes. The issues have been discussed substantially in domain of economics, management, psychology, management and accounting literature.

The rest of this paper is organized as follows. The next sections of this study discuss the hypotheses development, metaanalysis procedure, and results. The conclusion is provided at the last section.

\section{Hypotheses Development}

Studies in the relationship between intragroup cooperation, intragroup com- 
petition and performance use a similar dependent variable (i.e. performance) and similar independent variables (i.e. intragroup cooperation and competition). Those studies test the same proposition suggested by Deutsch (1949) that intragroup cooperation has higher performance than intragroup competition. The studies argue that intragroup cooperation outperform intragroup competition because the cooperative setting facilitates team members to exchange information to develop and to exploit the benefits of synergies and trusts that eventually improve the productivity.

The studies test the same proposition, however they use different experimental settings and different participants. The independent variables, intragroup cooperation and intragroup competition, are operationalized using different incentive systems. In intragroup cooperation, the participants are told that their incentive will be based on their group's productivity, while in intragroup competition the member's incentive will be based on the relative productivity of each member. The dependent variable, performance, is measured by the number of products produced by the groups.

Studies from business and accounting areas use experimental setting that resembles manufacturing works assembly (Young et al. 1992), or managerial problem solving (Ravenscroft and Haka 1993). Studies in educational and social psychology use experimental setting such as students' work on general task such as card game (Workie 1974), solving a social prob- lem and writing (Michael 1978; and Brown and Abram 1986).

In terms of participants in the experiments, studies from the business and accounting area use business and accounting major students, while studies from the educational and social psychological area use subjects with various educational backgrounds such as high school students (Brown and Abram 1980) and college students enrolled in psychology and sociology courses (Michaels 1978).

Johnson et al. (1981), based on their meta-analysis, claimed that the proposition that intragroup cooperation result in higher performance than that of intragroup competition was held for all subjects from different age groups, different educational backgrounds, and different tasks. Johnson et al.'s (1981) meta-analysis included studies using subjects with various educational backgrounds such as language, arts, reading, science, psychology, physical education, and math areas. However, the study did not include subjects with organizational, business and accounting areas.

In organizational, business, and accounting situations, members of an organization have common goals and interdependent tasks. Management approaches that expose the organization members to the common goals may increase the productivity. ${ }^{1}$ Lawler (1986), Birnberg and Snodgrad (1988) illustrate that cooperative behavior of workers and managers can reduce the cost of formal (bureaucratic) control systems. ${ }^{2}$ Cooperative values shared by the members of the organization replace the costly formal control

\footnotetext{
${ }^{1}$ Lawler (1986) illustrates the successful applications of the approaches in corporations such as Westinghouse and Honeywell.

${ }^{2}$ Birnberg and Snodgard (1998), based on their study on organizational culture in a number of Japanese and U.S. companies, illustrate that bureaucratic control system such as standard performance and formal rules can be reduced if the employees and managers share the cooperative values.
} 
system. For these reasons, this study hypothesizes that the proposition that intragroup cooperation outperforms intragroup competition is held for all subjects and settings including business and accounting subjects and settings.

Rosenthal and Rosnow (1991) argue that combining effect sizes or p-values is most easily justified if the effect sizes and p-values are statistically homogeneous. For that reason, the heterogeneity test is conducted before combining the effect sizes an $\mathrm{p}$-values. They suggest that extra consideration should be given when the effect sizes or $p$-values are statistically heterogeneous, especially if the results are in an opposite direction.

Thus, the first two hypotheses being tested are the following.

$H_{1}$ : The effect sizes and p-values of the studies that investigate whether intragroup cooperation outperforms intragroup competition are statistically homogeneous.

$\mathrm{H}_{2}$ : The combined effect sizes of studies investigating that intragroup cooperation outperforms intragroup competition is positive.

The other hypotheses being tested in this study address the possible intervening variables that include subjects' educational backgrounds, task interdependency, and gender. Business and accounting students often learn problem-solving methods in competitive situations. For example they learn how to increase market share of a company in competitive market, and how to bargain the transfer price with other divisions to increase the divisional profits. For that reason, psychology and sociology students may be more to cooperate than business and accounting students; and so that the effect of cooperation on productivity will be higher for psychology and sociology student than that for business and accounting students. Thus, it may be suggested that studies that use business students will have lower effect sizes than those than use psychology and sociology students, as stated in the following hypothesis.

$H_{3}$ : The effect sizes of studies using business students are different from that of studies using psychology and sociology students.

Intragroup cooperation may outperform intragroup competition under a condition when the task is interdependent. Task interdependence exists when a member needs another member's contribution to fulfill the task. Chase and Aquilano (1988) observed work-groups in manufacturing company and suggested that the benefit of intragroup cooperation increases when some members need other member's contribution to complete the works.

Task interdependency can be identified based on the nature of the task in the experiment. Certain tasks, such as judgmental problem solving and group writing, are considered more interdependent than technical tasks such as building toys (Driskell et al. 1987). Task interdependency is classified based on the characteristics of the tasks used, e.g. technical tasks such as building toys are classified as low interdependent tasks, and analytical tasks, such as solving problem and group writing ideas are classified as high interdependent tasks. Based on that reasoning, the fourth hypothesis being tested in the study is the following.

$H_{4}$ : The combined effect size of studies using interdependent tasks are greater than the combined effect size of studies using less interdependent tasks.

Previous research found that males tend to be more competitive than females (Maccoby and Jacklin 1974). The extent 
males and females tend to be more competitive or more cooperative may affect the productivity of competition or cooperation of male and female subjects. Female intragroup cooperation may result in higher productivity than male intragroup cooperation. Thus, this study hypothesizes the different effect size of intragroup cooperation and competition on performance for males and females group members.

$H_{5}$ : Studies using male subjects may have smaller effect size than that of studies using female subjects.

\section{Meta-Analysis Procedure}

This study uses meta-analysis and contrast analysis to test the hypotheses. Meta-analysis is an analysis of analysis; it is a methodology for quantitatively cumulating and integrating findings across studies. Rosenthal (1991) suggests that metaanalysis can be used for summarizing relationships, identifying moderating variables, and establishing new relationships. This study uses the summarizing function to test the first two hypotheses, and uses the identification of moderating variable function to test the order hypotheses.

This study follows Rosenthal (1991) and Rosenthal and Rosnow (1991) in computing effect sizes. Effect sizes are computed using Pearson's $r$ estimator. ${ }^{3}$ Before combining and comparing the effect sizes of the studies, each study is analyzed with respect to the construct, internal, statistical, and external validity. This analysis is important to determine the quality of the studies. Heterogeneity test is conducted by comparing the studies using diffuse test, to check if the studies provide the same results. The ESS meta-analysis program is used for combining and comparing the effect sizes and significant levels. ${ }^{4}$

The studies included in this metaanalysis are coded based on (1) the journal, title, author and year of publication; (2) statistical results to compute effect size; (3) dependent and independent variables; (4) experimental designs including the participants, task, and procedure.

\section{Meta-Analysis Results}

The studies included in the metaanalysis were retrieved from various journals such as Journal of Psychology, Journal of Experimental Social Psychology, The Journal of Social Psychology, Journal of Educational Psychology, and the Accounting Review. The meta-analysis also includes one study from the proceedings of the American Association of accounting (AAA) Annual Meeting that eventually published in Journal of Management Accounting Research. ${ }^{5}$

Originally, ten experimental studies are located. Three studies are excluded because they have different research designs and provide diffused $F$-test (i.e., the numerator degree of freedom is more than one). Of the seven studies included, one study provide two focused $F$-tests based on different samples (Michael 1978). The

\footnotetext{
${ }^{3}$ For studies that provide $F$ statistics with the numerator degree of freedom equals to one, the effect size $\mathrm{r}$ is computed as follows: $r=\sqrt{[f /(f+d f)]}$. For studies that provide t-test, the effect size $\mathrm{r}$ is computed as follows: $r=\sqrt{\left[t^{2} /\left(t^{2}+d f\right)\right]}$

${ }^{4}$ This program is intended for use with the text book "Essentials of Behavioral Research: Methods and Data Analysis" by Rosenthal and Rosnow (1991).

${ }^{5}$ Between the two version of the research reports (presented in conference and published in the journal), there is no major difference due to revision.
} 
study uses two samples, male and female students, and tests the relationship between intragroup cooperation and competition in each sample. Rosenthal and Rosnow (1991) suggest that two or more studies are not independent if the same subjects or sampling units are used for the studies or dependent variables. Considering the criterion and the domain of this meta-analysis study, Michael's (1978) study is considered as two independent studies. The coding results of these studies are presented in Table 1 and 2.

\section{Analysis of Internal, External and Construct Validity}

Internal validity refers to the degree of validity of a causal relationship between dependent and independent variables. In experimental studies, threats to internal validity come from sources such as history, maturation, instrumentation, selection, mortality, diffusion, and resentful demoralization (Rosenthal and Rosnow 1991; Isaac and Michael 1990; Cook and Campbell 1979). Experimental procedures of the studies included in the meta-analysis are examined to evaluate whether those threats of internal validity are controlled.

Almost all of the experiments in the seven studies used a post-test design and randomized the assignment of the participants into the treatment groups. ${ }^{6}$ Randomization enables the studies to control for the threats of internal validity. Using randomization, the experimenters assume that all the subjects are equal. The difference between treatment groups may exist only by chance and this type of difference is taken into account by the test of significance (Isaac and Michael 1990).
The use of post test design and randomization may adequately control the threats of internal validity. However, other threats should be considered. Cook and Campbell (1979) suggest some threats that randomization cannot rule out, e.g. demoralization and imitation of treatment. Demoralization refers to feeling of resentment by subjects that receive less desirable treatment. Being in a competitive situation may result in feelings of resentment, and in turn the feeling may influence their productivity. Thus, it might not be competitive situation that makes subjects (in the competitive treatment) become less productive (than their peers in cooperative situation), but because of their feelings of resentment and demoralization.

External validity refers to the generality of the results of the studies to other situations. Rosenthal and Rosnow (1991) and Cook and Campbell (1997) suggest three sources of external validity threats in experimental studies i.e. interaction of pretesting or history and treatment, interaction of setting and treatment, and interaction of selection and treatment. The experimental design used in the studies can control the first threat, but cannot control the second and third threat. In fact, this study addresses that cooperation outperform intragroup competition is held across different subjects, experimental tasks and settings (Type of tasks used in each study is listed in Table 1).

Construct validity refers to the existence of the dependent and independent variables, their causal relationship, and measures and manipulation of the variables (Cook and Campbell 1979). The studies included in the meta-analysis con-

\footnotetext{
${ }^{6}$ The exceptions are studies by Goldman et al. (1977) and Smith et al. (1957). The studies use post -test, but they do not fully randomize the assignment. The assignment is controlled so that there is no group with already acquainted members.
} 


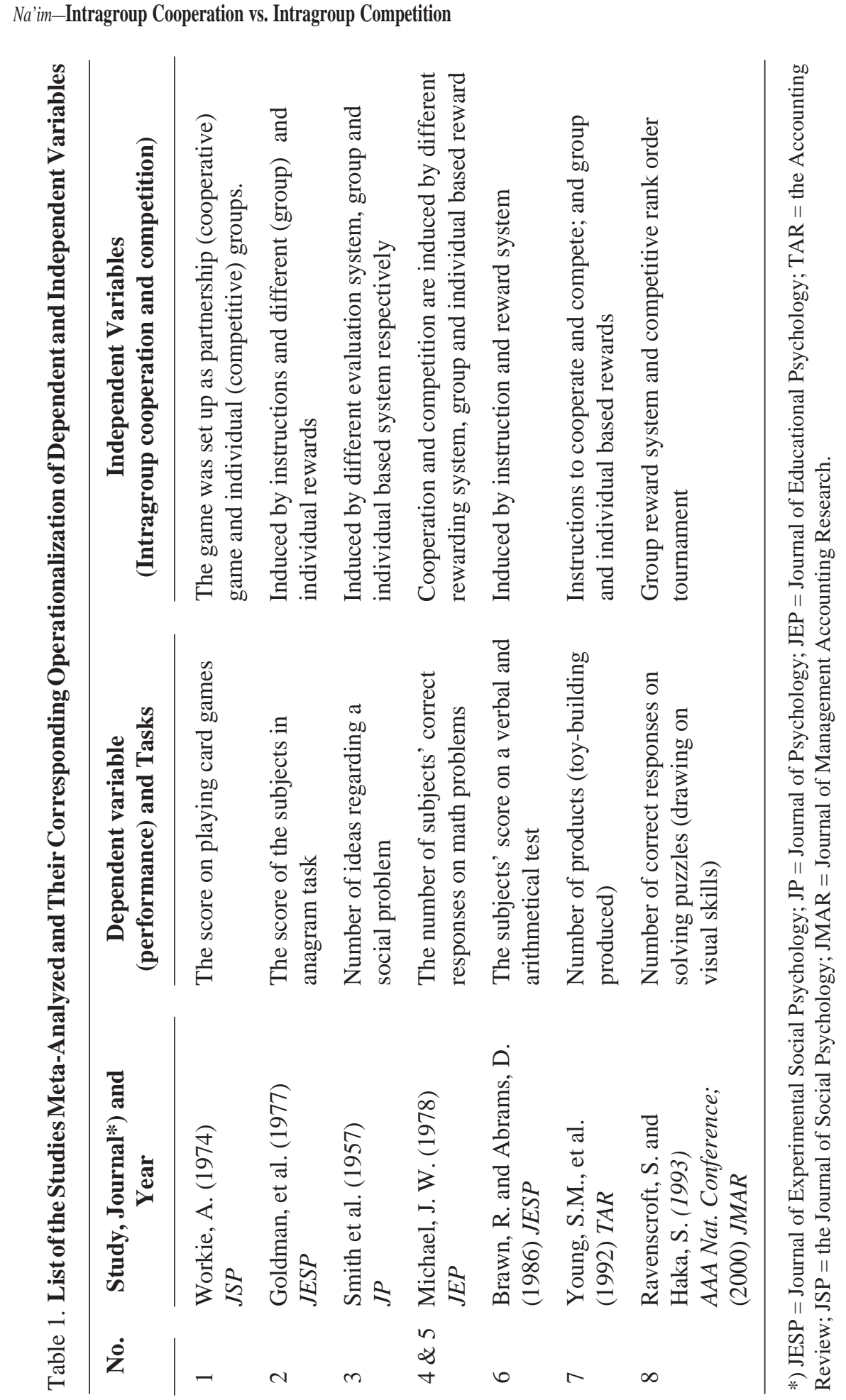


ducted adequate procedures to control the threats of construct validity such as pilot testing and manipulation checks and pilot studies are conducted in Young et al.'s (1992) and Ravenscroft and Haka's (1993) studies. In those studies, different subjects are used to check the effectiveness of experimental treatments. Internal manipulation checks are conducted in other studies, by questioning the experiment participants or by asking the participants to fill out a questionnaire.

Based on the analysis of internal, external, and construct validity of the studies, it is concluded the studies have similar quality, so that no weighting is needed for comparing and combining the studies (or each study is given weight of one).

\section{Results of Comparing and Combining the Studies}

Table 2 lists the studies that are compared and combined, with their reported $F$ and $t$ statistics, degrees of freedom, computed effect sizes $r$ and corresponding Fisher $z$-scores. The heterogeneity test for the studies results in $X^{2}(7)=9.94$, (p-one tailed=0.19); suggesting that the results of the studies are homogeneous, consistent with each other, supporting hypothesis one. Because the results of the studies are homogeneous, combining the effect sizes of the studies is justified.

Combining the effect sizes of the studies results in $r$ of 0.33 . Based on Cohen's criteria, the combined effect size indicates a moderate effect size (Rosenthal and Rosnow 1991). However, in business organizations, the effect size of 0.33 may be considered very important because the high competitiveness of market. The combined effect size is highly reliable, because the associated combined $p$-value is very impressive, i.e. $p=0.000000001$ (Fail safe number $[(\mathrm{p}=0.05)=147.91]$. Based on these results, the hypothesis that intragroup cooperation outperforms intragroup competition across different settings and subjects is supported.

\section{Contrast Analysis}

Contrast analysis is used to test the third, fourth, and fifth hypotheses. The third hypothesis predicts that the effect

Figure 1. Effect Sizes of Studies using Business and Psychology Student Subjects

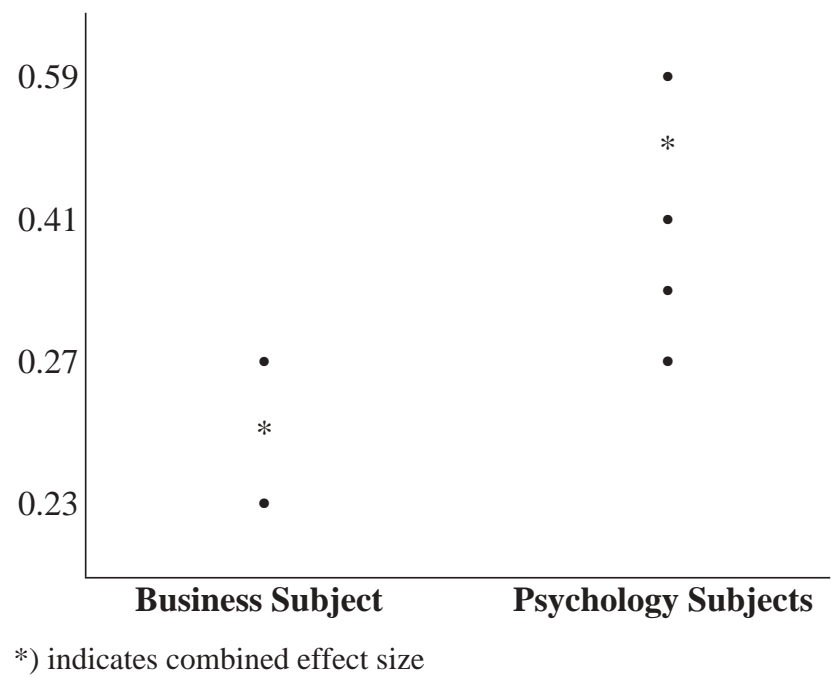


Na'im-Intragroup Cooperation vs. Intragroup Competition

Table 2. List of the Studies Meta-Analyzed and Their Corresponding Subjects, Scores on df, F, t, z, and Effect Size (r)

\begin{tabular}{|c|c|c|c|c|c|c|}
\hline No. & Study, Year & Subjects & df & $\mathbf{F} / \mathbf{t}$ & $\mathbf{Z}$ & $\mathbf{r}$ \\
\hline 1 & $\begin{array}{l}\text { Workie, A. } \\
\text { (1974) }\end{array}$ & Male high school students & $(1,57)$ & 7.99 & 0.365 & 0.350 \\
\hline 2 & $\begin{array}{l}\text { Goldman, et al. } \\
\text { (1977) }\end{array}$ & $\begin{array}{l}\text { Undergraduate students in } \\
\text { psychology }\end{array}$ & $(1,56)$ & 10.45 & 0.412 & 0.396 \\
\hline 3 & $\begin{array}{l}\text { Smith et al. } \\
\text { (1957) }\end{array}$ & $\begin{array}{l}\text { College students in } \\
\text { psychology }\end{array}$ & 28 & $\mathrm{~T}=3.96$ & 0.599 & 0.590 \\
\hline $\begin{array}{l}4 \& \\
5\end{array}$ & $\begin{array}{l}\text { Michael, J.W. } \\
\text { (1978) } \\
\text { Michael, J.W. } \\
\text { (1978) }\end{array}$ & $\begin{array}{l}\text { Male Undergraduate } \\
\text { Female Undergraduate } \\
\text { Student in sociology }\end{array}$ & $\begin{array}{l}(1,66) \\
(1,66)\end{array}$ & $\begin{array}{l}6.73 \\
4.45\end{array}$ & 0.310 & 0.304 \\
\hline 6 & $\begin{array}{l}\text { Brown, R. and } \\
\text { Abrams, D. } \\
\text { (1986) }\end{array}$ & High school students & $(1,196)$ & 4 & 0.141 & 0.141 \\
\hline 7 & $\begin{array}{l}\text { Young, S.M. } \\
\text { et al. (1992) }\end{array}$ & $\begin{array}{l}\text { Undergraduate students } \\
\text { in accounting }\end{array}$ & $(1,67)$ & 3.91 & 0.234 & 0.234 \\
\hline 8 & $\begin{array}{l}\text { Revenscroft, S. } \\
\text { and Haka, S. } \\
\text { (1993) }\end{array}$ & $\begin{array}{l}\text { Undergraduate students } \\
\text { in business }\end{array}$ & $(1,94)$ & 7.74 & 0.277 & 0.275 \\
\hline
\end{tabular}

Comparison of the effect sizes results in $\mathrm{X}^{2}(7)=9.94(\mathrm{p}$, one-tailed $=0.19)$.

Comparison of significant levels results in $\mathrm{X}^{2}(7)=2.15(\mathrm{p}$, one-tailed $=0.95)$.

Combining the effect sizes results in $\mathrm{Zr}=0.34$; and $\mathrm{r}=0.326$.

Combining the significant levels results in $\mathrm{Z}=7.26(\mathrm{p}=000000001)$

size of studies using business students is different from that of studies using education, psychology and sociology students' subjects. The effect size of studies with psychology and sociology students will be higher than those using business and accounting students.

From all of the studies located, two studies use business and accounting students, and four studies use education, psychology and sociology students. Heterogeneity test of the studies in each group results in $Z=0.27$, (p, one-tailed $=0.39$ ) for the former, and $X^{2}$ studies within each group are homogeneous. The combined effect size of studies using business and accounting students is found lower $(\mathrm{r}=$ 0.255 ) than the combined effect sizes of studies using psychology and sociology students $(r=0.397)$. Contrast analysis of studies results in a Z-value of 1.421, (pvalue $=0.07$ ). Figure 1 presents the effect size of each study within each group and combined effect size of each group. The detail computations of the contrast analysis are in Table 3. Based on this result, hypothesis 3 is marginally supported. 
Gadjah Mada International Journal of Business, September 2004, Vol. 6, No. 3

Table 3. Contrast Analysis to Compare the Effect Size of Studies Using Psychology and Sociology Students with Those Using Business and Accounting Students

\begin{tabular}{|c|c|c|c|c|c|}
\hline No. & Study & $\mathrm{N}$ & $\mathrm{W}$ & $\mathrm{Z}_{\mathrm{j}}$ & $\Lambda_{\mathrm{j}}$ \\
\hline & \multicolumn{5}{|l|}{ Psychology/Sociology } \\
\hline 1 & Goldman et al. 1977 & 58 & 53 & 0.412 & 1 \\
\hline 2 & Smith et al. 1957 & 29 & 24 & 0.678 & 1 \\
\hline 3 & Michael, J. W. 1978 & 68 & 63 & 0.310 & 1 \\
\hline 4 & Michael, J. W. 1978 & 68 & 63 & 0.255 & 1 \\
\hline & \multicolumn{5}{|l|}{ Business and Accounting } \\
\hline 1 & Ravenscroft and Haka, 1993 & 97 & 92 & 0.322 & -2 \\
\hline 2 & Young et al. 1992 & 69 & 64 & 0.234 & -2 \\
\hline
\end{tabular}

$Z$-value $=\Sigma \alpha_{\mathrm{j}} \mathrm{Z}_{\mathrm{j}} / \mid\left(\Sigma \alpha_{\mathrm{j}}^{2} / \mathrm{W}_{\mathrm{j}}\right)$, where $W_{\mathrm{j}}$ is $N-K$,

Where $N$ is sample size, and $K$ is number of studies minus one

$=1.447$. $(\mathrm{p}$ one-tailed $=.0708)$

Figure 2. Effect Sizes of Studies Using Low and High Interdependence Tasks

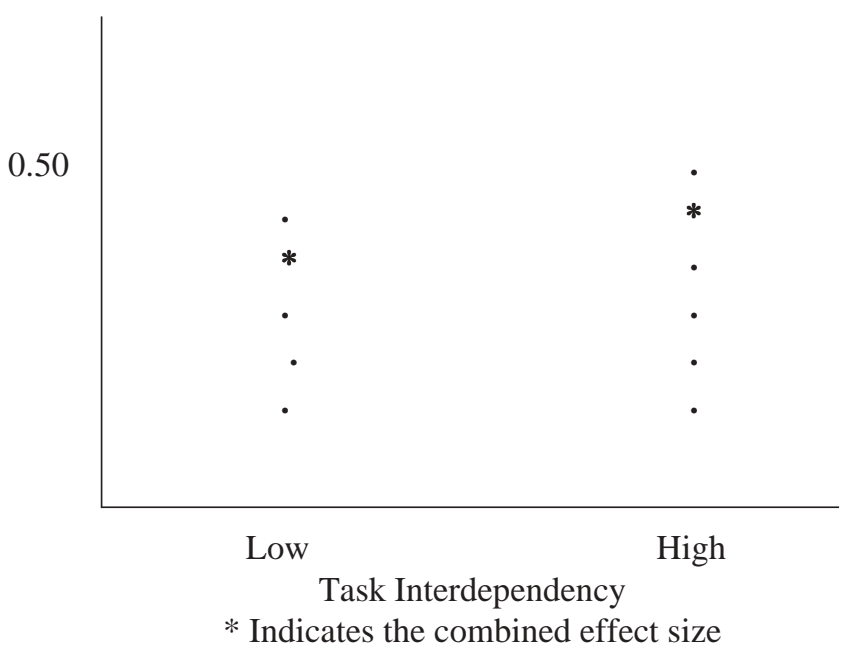

The fourth hypothesis predicts that there is a linear relationship between effect size of the studies and the degree of interdependency of tasks used in the experiment. Tasks interdependency is deter- mined subjectively based on the general criteria that task that need analytical and judgmental reasoning are more interdependent than technical tasks (Driskell et al. 1987, and Chase and Aquilano 1988). 
Based on this criterion and examining the experimental procedure of each study, four studies are categorized as having low task interdependency and four studies are categorized as having high tasks interdependency.

Test of heterogeneity of the studies in each group results in that the studies in low interdependence tasks are homogeneous $\left[\mathrm{x}^{2}(3)=1.22\right.$, $(\mathrm{p}$ one-tailed $\left.=0.75)\right]$; but the studies in high interdependence task are not homogeneous $\left[\mathrm{x}^{2}(3)=7.74\right.$, $(\mathrm{p}$ one-tailed $=0.05)]$. This result suggests that combined effect size of the studies in high interdependence should be interpreted cautiously.

The combined effect size for studies in low and high interdependence task is 0.31 and 0.34 , respectively. The effect sizes of the studies in each group of low and high interdependence task are presented in Figure 2.

Contrast analysis results in a $Z$-value of 0.25 ( $p$ one-tailed $=0.40$ ). Thus, hypothesis four is not supported. The detail computation of the analysis is provided in Table 4. This result should be considered cautiously because of that the categorization of tasks interdependency is based on the subjective and rough criteria.

The fifth hypothesis predicts the difference between effect size of studies that use male subjects and female subjects. Three studies provided adequate data for this analysis. Two studies have male subjects, and one study has female subjects. Contrast analysis results in Z-value of 1 . 667 ( $\mathrm{p}$ one-tailed $=0.05$ ), suggesting that studies using male subjects have significantly different effect size than that using

Table 4. Contrast Analysis Examining Linear Relationship between the Degree of Task Interdependence and Effect Size

\begin{tabular}{|c|c|c|c|c|c|c|}
\hline No & Study & $\mathbf{H} / \mathbf{L}^{*}$ & $\ddot{\mathbf{E}}_{\mathrm{j}}$ & $\mathbf{N}$ & $\mathbf{W}$ & $\mathbf{Z}_{\mathrm{j}}$ \\
\hline 1 & Young, S. M. (1992). TAR & $\mathrm{L}$ & -1 & 69 & 62 & 0.234 \\
\hline 2 & Workie, A. (1974). JSP & $\mathrm{L}$ & -1 & 60 & 53 & 0.365 \\
\hline 3 & $\begin{array}{l}\text { Ravenscroft and Haka. (1993). } \\
\text { AAA NAT Conference }\end{array}$ & $\mathrm{L}$ & -1 & 97 & 90 & 0.332 \\
\hline 4 & Goldman, et al. (1977). JESP & $\mathrm{L}$ & -1 & 58 & 51 & 0.412 \\
\hline $\begin{array}{l}5 \\
6\end{array}$ & $\begin{array}{l}\text { Michael J. W. (1978). JEP } \\
\text { Michael J. W. (1978). JEP }\end{array}$ & $\begin{array}{l}\mathrm{H} \\
\mathrm{H}\end{array}$ & $\begin{array}{l}1 \\
1\end{array}$ & 68 & $\begin{array}{l}61 \\
61\end{array}$ & $\begin{array}{l}0.310 \\
0.234\end{array}$ \\
\hline 7 & Brown and Abram, D. (1986) & $\mathrm{H}$ & 1 & 198 & 191 & 0.141 \\
\hline 8 & Smith et al. (1957). $J P$ & $\mathrm{H}$ & 1 & 29 & 22 & 0.678 \\
\hline
\end{tabular}

*) The first four studies that use tasks that involve toy building, solving puzzles, playing card game, and writing are classified as having low interdependence task; while the rests that use math problems, verbal and arithmetic problems, and generating idea regarding social problems are classified as having high interdependence tasks.

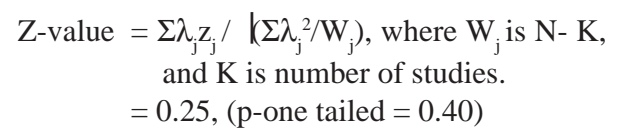


Gadjah Mada International Journal of Business, September 2004, Vol. 6, No. 3

Table 5. Contrast Analysis to Examine the Effect Size Difference between Studies with Male Subjects and Female Subjects

\begin{tabular}{|c|c|c|c|c|c|}
\hline No & Study & F/M Sample & $\mathbf{N}$ & $\ddot{\mathrm{e}}_{\mathrm{j}}$ & $\mathbf{z}_{\mathbf{j}}$ \\
\hline 1 & Workie, A. (1974) & M & 60 & 1 & 0.365 \\
\hline 2 & Michael, J. W. (1978) & M & 68 & 1 & 0.310 \\
\hline 3 & Michael, J. W. (1978) & $\mathrm{F}$ & 68 & -2 & 0.255 \\
\hline
\end{tabular}

Z-value $=\Sigma \lambda_{\mathrm{j}} \mathrm{Z}_{\mathrm{j}} /\left(\Sigma \lambda_{\mathrm{j}}^{2} / \mathrm{W}_{\mathrm{j}}\right)$, where $\mathrm{W}_{\mathrm{j}}$ is N- K , and $\mathrm{K}$ is number of studies (see Table 2 for $\mathrm{Z}$-value).

$=1.667,(\mathrm{p}$-one tailed $=0.475)$

female subjects. The studies with male subjects have higher effect size $(0.33)$ than those using female subjects $(0.255)$. Table 5 provided the detail of the computation in this contrast analysis.

The result contradicts that predicted, i.e. studies with male subjects would have lower effect size than studies with female subjects. One explanation of this contradiction may be the nature of the task used in the two of three studies analyzed which is solving math problem. Fennema and Sherman (1977) suggest that math is male typed subject, so that male individuals are more motivated in solving math problem than female individuals.

This result should be interpreted cautiously, because the number of studies included in the analysis is too small (3 studies), and female subjects are represented by only one study.

\section{Conclusion}

This study examined the proposition if intragroup cooperation outperforms intragroup competition is held across different subject educational backgrounds. Using meta-analysis, this study found supports for the proposition. Intragroup cooperation outperforms intragroup competi- tion across the backgrounds of the experimental subjects i.e. education, social psychology, and business and accounting. The meta-analysis conducted in this study indicates a moderate effect size of 0.33 . This effect size is smaller than the previous study that reported an effect size of 0.78 (Johnson et al. 1981). The difference may be caused by the small sample of this study.

The study also found that studies with psychology and sociology student subjects result in higher effect size than studies with business and accounting student subjects. This indicates that the extent intragroup cooperation results in higher performance than intragroup competition is larger for psychology and sociology students than for business and accounting students. One explanation of this result might be that business and accounting students have more training in dealing with competitive situations than their peers in psychology and sociology.

The finding of this study adds evidences to the cooperation theory, and provides support for the effects of the background of experimental subjects on the extent the cooperation schemes affect the performance. This also adds explanation to group dynamic issues. Nature of the 
Na'im-Intragroup Cooperation vs. Intragroup Competition

group members and schemes of works among the members explain to the outputs of the groups.

Results of this study should be considered cautiously for two factors. The study has very limited sample, and second, the retrieval of the studies included in the meta-analysis is arbitrary.

\section{References}

Birnberg, J.G., and C. Snodgrass. 1998. Culture and Control: A Field study. Accounting, Organization and Society 13 (5): 447-464.

Brown, R. and Abrams, D. 1986. The Effect of intergroup similarity and goal interdependence in intergroup attitudes and task performance. Journal of Experimental Social Psychology 22: 78-92.

Chase, R., and N. Aquilano. 1988. Production and operations Management-A life Cycle Approach. Homewood, IL: Richard D. Irwin

Cook T.D., and Campbell, D.T. 1979. Quasi Experimentation, Design and Analysis Issues for field Settings. N.J.: Houghton Mifflin Company.

Deutsch, M. 1949. An experimental study of the effects of cooperation and competition. In Tjosvold, D. 1984. Cooperation theory and organization. Human Relation 9 : 743767.

Driskell, J.E., R. Hogan, and E. Salas. 1987. Personality and group performance. In Group Processes and Intergroup Relations. Edited by Hendrick, C. California: Sage.

Fennema, E., and J. Sherman. 1977. Sex related differences in mathematics achievement, spatial visualization and affective factors. American Educational Research Journal 14: $51-71$.

Goldman, M., J. W. Stockbaurer, and T. G. McAuliffe. 1977. Intergroup and intragroup competition and cooperation. Journal of Experimental Social Psychology 13: 81-88.

Issac, S., and W. B. Michael. 1990. Handbook in Research and Evaluation (2 ${ }^{\text {nd }}$ ed.). California: Edit Publishers.

Johnson, D. W., G. Maruyama, R. Johnson, and D. Nielson. 1981. Effects of cooperative, competitive, and individualistic goal structures on achievement: a meta-analysis. Psychological Bulletin 89: 47-62.

Lawler, E.L. 1986. High Involvement Management. San-Fransisco: Jossey-Bass.

Maccoby, E. E., and C. N. Jacklin. 1974. The Psychology of Sex Differences. Stanford, California: Stanford University Press.

Michael, J. W. 1978. The effects of differential rewarding and sex on math performance. Journal Educational Psychology 4: 565-573.

Ravenscroft, S. and S. Haka, 1993. Incentive plans and opportunities for information sharing. Working Paper. Michigan State University, Michigan. 
Ravenscroft, S. and S. Haka, 1996. Incentive plans and opportunities for information sharing. Behavioral Research in Accounting 8:114-133.

Rosenthal, R. 1991. Meta Analytic Procedures for Social Research. CA: Sage.

Rosenthal, R., and R. L. Rosnow. 1991. Essentials of Behavioral Research: Methods and Data Analysis. New York: McGraw Hill.

Smith, A. J., H. E. Madden, and R. Sobol. 1957. Productivity and recall in cooperative and competitive discussion groups. The Journal of Psychology 9: 193-204.

Tjosvold, D. 1984. Cooperation theory and organization. Human Relation 37: 743-767.

Workie, A. 1974. The relative productivity of cooperation and competition. The Journal of Social Psychology 92: 225-230.

Young, S. M., J. Fisher, and T. M. Lindquist. 1992. The effects of intergroup competition and intragroup cooperation on slack and output in manufacturing setting. The Accounting Review 3: 466-481. 